\title{
CRÍTICA LITERÁRIA E MEDIAÇÃO CULTURAL: NESTOR VÍTOR E 0 SEU PAPEL NA DIVULGAÇÃO DA OBRA DE CRUZ E SOUSA
}

\section{LITERARYCRITICISMAND CULTURAL MEDIATION: NESTOR VITOR ANDHIS ROLE IN THEDISSEMINATIONOF CRUZ E SOUSA'SWORK}

José Fábio Silva'

RESUMO: O artigo aborda o papel exercido pela crítica literária na propagação e canonização da obra do poeta João da Cruz e Sousa na virada do século XIX para o século XX. Para tanto, partiremos da trajetória intelectual do crítico literário Nestor Vítor e de sua atuação junto ao grupo de escritores simbolistas brasileiros. Abordaremos não só seu trabalho como crítico literário, mas também a ação como intelectual mediador, atuante na publicação e na disseminação da obra de Cruz e Sousa. Intelectual é aqui compreendido como o sujeito responsável tanto pela produção como pela disseminação de ideias, visando ou não uma intervenção política ou social.

PALAVRAS-CHAVE: História Intelectual; Crítica literária; Simbolismo.

ABSTRACT: The article discusses the role played by literary criticism in the propagation and canonization of the work of the poet Joano da Cruz e Sousa at the turn of the 19th century to the 20th century. To do so, we will start from the intellectual trajectory of the literary critic Nestor Vítor and his performance with the group of Brazilian symbolist writers. We will approach not only his work as a literary critic, but also the action as a mediator, acting in the publication and dissemination of Cruz e Sousa's work. Intellectual is understood as the subject responsible for both the production and the dissemination of ideas, with or without a political or social intervention.

KEYWORDS: Intellectual History; Literary criticism; Symbolism.

\section{CONSIDERAÇÕES INICIAIS}

No mês de abril de 1927, uma "polêmica" envolvendo o poeta Alberto de Oliveira (1857-1937) e o crítico literário Nestor Vítor (1868-1932) circulou nas páginas do jornal $O$ Globo. Os fatores que motivaram a questáo envolviam o reconhecimento de Cruz e Sousa (1861-1898) como um dos grandes poetas brasileiros. A polêmica desenvolveu-se em três artigos: $A$ infantilidade de um príncipe (11-4-1927), de Nestor Vitor; $\grave{A}$ propósito

Doutorando em História pelo PPGH da Universidade Federal de Goiás (UFG). Bolsista CAPES. E-mail: fabiojfs@hotmail.com 
de Cruz e Sousa: uma comunicação do poeta Alberto de Oliveira (18-4-1927); e a tréplica do primeiro, Nestor Vitor explica e insiste (25-4-1927). Essa discussão, à primeira vista, poderia ser interpretada como um resquício da oposição entre parnasianos e simbolistas que marcou a vida literária brasileira na virada do século XIX para o século XX. Essa tese ganha ainda maior respaldo ao lembrarmos que Alberto de Oliveira, membro da tríade parnasiana brasileira junto com Olavo Bilac (1865-1918) e Raimundo Correa (18591911), era considerado o Príncipe dos poetas brasileiros e Nestor Vítor, amigo de Cruz e Sousa, figurava como o critico oficial do simbolismo no Brasil.

Ao observarmos mais de perto o conteúdo das supracitadas publicações, entretanto, percebemos mais do que uma disputa "anacrônica" entre parnasianos e simbolistas. O conteúdo da discussão envolveu não só a veracidade de uma história, mas também o papel exercido pela crítica literária na propagação e canonização da obra de Cruz e Sousa. O papel de Nestor Vítor nesse processo envolve bem mais do que o seu trabalho como intelectual, mas também a função que tomou para si de divulgador da obra do Poeta Negro.

O objetivo deste trabalho é pensar a mediação crítica da obra de Cruz e Sousa, a partir da trajetória intelectual de Nestor Vítor e de sua atuaçáo no grupo dos novos. Abordaremos não só seu trabalho como crítico literário, mas também a ação como intelectual mediador, atuante na publicação e na disseminação da obra de Cruz e Sousa. Compreendemos intelectual como sujeito responsável tanto pela produção como pela disseminaçáo de ideias, visando ou não uma intervenção política ou social. "Sendo assim, tais sujeitos podem e devem ser tratados como atores estratégicos nas áreas da cultura e da política que se entrelaçam, não sem tensões, mas com distinções, ainda que historicamente ocupem posição de reconhecimento variável na vida social” (GOMES; HANSEN, 2016, p. 10).

\section{UMA POLÊMICA ANACRÔNICA}

O estopim da polêmica supracitada se deu devido a uma história contada por Alberto de Oliveira em roda de amigos e em entrevista concedida ao Jornal do Brasil, "que dava como sendo a gênese da glória e celebridade que o nome de Cruz e Sousa vinha alcançando" (VITOR, 1979, p. 190). Nestor Vítor assim relata a anedota:

Dizia ele que a princípio, até depois da morte do poeta, Sílvio Romero o tinha em conta de burro. Mas que uma vez, encontrando-me eu com o grande crítico em casa de Melo de Morais Filho, seu grande amigo, casa em que ele estava passando alguns dias, consegui persuadi-lo de que ele incorria em erro. Mas de que modo? Antes de tudo enchendo-o de comiseração por Cruz. Pintando a vida desgraçada do poeta. A miséria partilhada por ele com sua mulher e quatro filhos, toda essa gente sustentada por ganhos ridículos, numa secçáo da Estrada de Ferro Central, onde pouca era a consideração tributada ao pobre homem.

Então Sílvio ficara comovido, pedira-me que eu lesse os versos de Cruz e Sousa e na proporção que os lia ouvindo arrebatava-se, tocado, no fundo, pela piedade, que lhe obnubilara o espírito por completo.

Mais tarde, Romero - explica Alberto - escrevendo um ensaio sobre literatura para o Livro do Centenário, elevava então ao último céu o poeta.

E foi daí - concluía o maldoso - que veio propriamente a voga de Cruz e Sousa (VITOR, 1979, p. 190). 
Nestor Vítor não negou tal encontro com Sílvio Romero, mas ressaltou que não leu "verso nenhum" na ocasião. Para enfatizar o seu ponto de vista, levantou a questão: se, caso Sílvio Romero, fez uma crítica positiva a Cruz e Sousa por comiseração, "por que é que em toda a sua vasta obra crítica não se encontra outro caso?” (VITOR, 1979, p. 192). E ainda, "se fora por sentimentalismo que Sílvio se rendera, devia no seu juízo crítico figurar qualquer conceito que a crítica dos outros náo sancionasse antes ou depois”. Em defesa de Cruz e Sousa, busca esclarecer o chamou de "grosseiro erro histórico em que redundava essa gênese inventada” (VITOR, 1979,191-192). Sem negar a importância da crítica feita por Sílvio Romero, afirma que "Cruz e Sousa é a muitos respeitos o melhor poeta que o Brasil tem produzido" e que "nele se acha o ponto culminante da lírica brasileira após 400 anos de existência" (VITOR, 1979, 192-193) - enfatiza que o poeta "há muito conquistara o entusiasmo de quase toda a mocidade brasileira nas letras" e "vinha fazendo o seu caminho, lento, mas com segurança, como acontece com quase todos os grandes inovadores". E completa adiante "sem ele [Silvio Romero], ou sem mim, como sem outros, o grande Negro chegaria aonde estâ" (VITOR, 1979, 191). Em relação a condição financeira de poeta, Nestor Vítor alfineta ao lembrar que, naquela época, "Alberto de Oliveira se irmanava mais ou menos com ele na mesma gloriosa pobreza" (VITOR, 1979, p. 192).

Em resposta, Alberto de Oliveira cita trecho de Páginas de crítica (1920), de Medeiros e Albuquerque, no qual estava reproduzida a supracitada anedota. Na obra em questão, Medeiros e Albuquerque expóe duramente o seu ponto de vista em relação a Sílvio Romero ao afirmar que este era um "critico excellente para as largas idéias, as amplas generalisaçóes. Critico instável, parcialissimo para as apreciaçóes individuaes” 2 (1920, p. 08). Alberto de Oliveira ainda acrescenta:

\footnotetext{
Este mesmo conceito, mais alongadamente e com pormenores, sobre Silvio Romero ou sobre até onde o levava seu coração, ouvi-o eu a Melo Morais Filho; Medeiros ouviu-o por sua vez ou diretamente do mesmo velho cronista, de quem, como eu, era amigo, ou a mim, que talvez lho comunicasse (OLIVEIRA, 1979, p. 356).
}

O Príncipe dos poetas, assim, coloca em dúvida de quem partiu a autoria da história, mas não nega o seu conteúdo. Em sua tréplica, Nestor Vítor admite que não leu o citado livro de Medeiros e Albuquerque. "Em todo caso, quem forneceu a fábula a Medeiros? Foi provavelmente o próprio Sr. Alberto, como este é o primeiro a admitir" (VITOR, 1979, p. 194). Em relação a Medeiros e Albuquerque acrescenta que "não há quem ignore como é paradoxal e cheio de singularidade em seus gostos", em relação a Cruz e Sousa "acha-o quase que absolutamente sem ideias, por conseguinte oco" (VITOR, 1979, p. 194). Apesar de tal opinião "uma vez me contou que os livros de Cruz eram dos que andam à sua cabeceira, pela extraordinária musicalidade, própria daqueles versos, que lhe fazia bem antes de dormir". Por fim, Nestor Vítor ironiza "basta saber que ele [Medeiros e Albuquerque] acha irrisório afirmar-se ter Cruz e Sousa aberto uma nova época na história da nossa literatura" (VITOR, 1979, 195). Posteriormente, busca demonstrar que o Poeta Negro náo obteve destaque e importância na literatura nacional graças a Silvio Romero, mas ao contrário, os elogios

Optou-se por manter a grafia da época nas citaçôes. 
por parte de Romero só foram feitos devido à importância junto ao meio literário da qual já gozava o autor de Broquéis.

Está vendo, pois, o Sr. Alberto que o caso Cruz e Sousa-Sílvio Romero só ganhou real importância por sua causa. Porque o Sr. Alberto é Príncipe e um dos chefes do parnasianismo no Brasil. É feio, nessas condiçôes, vir atacar um morto como o Poeta Negro (VITOR, 1979, p. 195).

Ao tentar desmentir o conteúdo da história contada por Alberto de Oliveira, Nestor Vítor náo partia só em defesa do seu falecido amigo, mas, sobretudo, do legado que ele e outros integrantes do movimento associado ao simbolismo e ao decadismo buscaram construir nas letras do Brasil. Comparado ao parnasianismo, o movimento simbolista obteve pouca repercussáo no cenário brasileiro. "Para grande parte dos escritores e críticos que viveram nos primeiros decênios do século $X X$, a poesia simbolista não interpretava elementos brasileiros, locais, como fizeram nossos românticos" (BRANDÁO, 2010, 119). Outra acusação feita ao movimento é o de não continuidade, por não possuir "o potencial emancipatório do simbolismo (decadismo) francês, o movimento simbolista brasileiro permaneceu estagnado, sem repercussóes profundas nas estéticas imediatamente posteriores". (BRANDÃO, 2010, p. 129). Exceção a tal afirmação é o caso da revista Festa, na qual os seus idealizadores "fossem criticos literários, poetas, contistas, folcloristas ou cronistas, assinavam a raiz simbolista de sua formação e entendendo-a como signo de brasilidade e modernidade". (GOMES, 2004, 95). A atuação de Nestor Vítor durante o modernismo, o mostrará "como crítico atento aos novos valores e, inclusive, participando das atividades do grupo 'Festa' onde aparece como mestre da nova geraçâo" (CAROLLO, 1981, pp. 2-3).

A polêmica acima descrita se mostra uma oportunidade de pensar tanto as relaçóes pessoais e profissionais estabelecidas entre intelectuais daquele período, quanto as formas de produção, recepção e mediação do que eles próprios produziam. Ou seja, o papel do intelectual como mediador cultural da produção artística. Dessa forma, muito mais do que apontar a "verdadeira" versão de uma anedota envolvendo literatos, poderemos vislumbrar, em meio a essa complexa teia de relaçóes e posiçóes intelectuais, o papel exercido pelo simbolismo no desenvolvimento da literatura brasileira. Assim como ocorreu com o simbolismo, a obra de Cruz e Sousa também passou por um lento processo de aceitação por parte da crítica literária. Dessa forma, podemos pensar a recepçáo de sua obra pela crítica em três momentos distintos. O primeiro (1883-1898), abrange a fase "heroica" de implantação do simbolismo no Brasil (CAROLLO, 1981), se estende do lançamento de Missal e de Broquéis até a morte do poeta. Com raras exceçóes, somente os intelectuais ligados ao grupo dos simbolistas reconheceram incondicionalmente a obra do poeta. $\mathrm{O}$ segundo (1898-1930), marca o período em que a sua obra passou gradativamente a ser reconhecida e comentada no meio literário brasileiro e o autor firmou-se no cânone literário brasileiro.

Evidencia-se a atuação de Nestor Vítor que, além de divulgar a obra do poeta, dialogou com as interpretações feitas pela crítica. Nessa fase de "serenidade", segundo definição do próprio Nestor Vitor, "o crítico passa a apontar para a 'caduquice do simbolismo' e a perceber as possiveis qualidades de seus epilogos a partir do descomprometimento de 'escola', ou seja, 
das exterioridades e extravagâncias" (CAROLLO, 1981, p. 02).Destacam-se, também, o lançamento de livros inéditos de Cruz e Sousa, de sua obra completa em 1923, a menção de Sílvio Romero no Livro do centenário (1900), o discurso de posse de Félix de Pacheco na Academia Brasileira de Letras (1913), a citação de Ronald de Carvalho em Pequena história da literatura brasileira (1918). O terceiro, a partir de 1930, compreende o momento em que Nestor Vítor encerrou a sua produção intelectual. Destaca-se a atuação de Andrade Murici e Tasso da Silveira na constante revisão da obra de Cruz e Sousa e do simbolismo em geral, pela crítica e estudos acadêmicos sobre a obra do poeta. Essa divisão visa apenas organizar teoricamente a maneira como a obra do poeta foi recebida pela crítica e o meio intelectual, náo coincidindo necessariamente com a recepçáo de suas obras pelo público leitor em geral.

\section{OS PRECURSORES DO SIMBOLISMO BRASILEIRO E O MOVIMENTO LITERÁRIO DE 1893}

Ao deixar o seu estado natal, o Paraná, e mudar-se definitivamente para o Rio de Janeiro em 1891, Nestor Vítor encontrou um ambiente intelectual que ensaiava gritos de renovação, diferente da primeira vez que esteve na cidade, em 1888, na qual "o parnasianismo, no verso, e o naturalismo, na prosa, dominavam sem contraste" (VITOR, 1979, p. 76). Influenciados "pelos sinais de inquietação cultural que inserem notícias e informações divulgando as últimas transformaçóes operadas na literatura europeia" (CAROLLO, 1980, p. 81) os rapazes que, em 1891, se agruparam em torno da Folha Popular "foram os primeiros a introduzir a nova moda poética no Brasil". (GARCEZ, 1983, 100). Esses rapazes se auto intitulavam grupo dos novos e militavam também em revistas de curta circulaçáo e năo representavam um todo homogêneo. Com cartas de apresentaçáo assinadas por seu conterrâneo Emílio de Meneses, Nestor Vítor passou a colaborar com revistas e jornais do Rio e do Paraná. Exerceu também, a convite de Fanor Cumplido, as funçôes secretário da Companhia Metropolitana do Paraná. Conheceu também nesse período Alberto de Oliveira, Medeiros e Albuquerque e Olavo Bilac, estreitando relaçôes principalmente com Maurício Jubim, Virgílio Várzea, Gonzaga Duque, Tibúrcio de Freitas e outros que vieram a ser os seus companheiros junto ao movimento simbolista.

Antes, porém, da formaçáo do grupo dos Novos, a ideia dessa nova estética literária promovida pelo manifesto do simbolista publicado, em 1886 por Jean Moréas, havia chegado em outras regióes do país. No próprio Rio de Janeiro, ainda em 1887, o responsável pelas primeiras notícias em relação a tal concepção estética foi Medeiros de Albuquerque ao trazer obras de "Rimbaud, Verlaine, Mallarmé e outros 'decadentes' (como então se chamavam), (...) proporcionara com notícias a respeito e as suas malsinadas Cançóes da Decadência, completamente alheias ao verdadeiro espirito daquele grupo francês" (VITOR, 1979, p. 78). No Paraná, especialmente em Curitiba, os escritos dos simbolistas franceses e belgas eram divulgados por Joáo Itiberê da Cunha (Jean Itibere), que estudava em Bruxelas desde 1880 e cultivava amizade com integrantes do movimento na Europa. São Paulo também se constitui como local de divulgaçáo das ideias simbolistas, sobretudo por meio dos jornais 
O Mercantil, Correio Paulistano e Estado de São Paulo e de pequenas revistas surgidas entre 1881 e 1889, "a maioria produçóes de estudantes de Direito" (CAROLLO, 1980, p. 217).

Antes de ser conhecido no Rio de Janeiro, Baudelaire já era lido em São Paulo entre esses estudantes. Por meio de um deles, o seu amigo Emiliano Perneta, Nestor Vítor entrou em contato com o autor de Flores do Mal. O crítico confessa que nem a ele e nem a Emiliano Perneta "esse grande precursor do simbolismo [Baudelaire] contaminou desde logo a ponto de levar-nos a evitar contato com os representantes do único verso ainda entáo tido por moderno entre nós". (VITOR, 1979, 76). Nessa época, estendeu "suas relaçóes e passou a conhecer grande parte da roda literária e jornalistica do momento, circulando entre eles ainda como um simples observador". (CARVALHO, 1997, p. 07). Nomeado vice-diretor do Internato do Ginásio Nacional, posteriormente, Colégio Dom Pedro II, lecionou disciplinas do curso de Letras ao lado de Sílvio Romero e João Ribeiro. José Veríssimo, que não era simpático às ideias simbolistas, era diretor do Externato do Ginásio Nacional. A pedido de Quintino Bocaiúva, passou a colaborar no jornal O Pais.

Até por volta de 1893, o movimento simbolista (ou o grupo que pode ser vinculado ao que se compreende como o simbolismo) estava em formação e carecia de fundamentaçáo das ideias por eles defendidas. Os representantes da literatura consagrada utilizavam termos como "novos", "decadentes" ou "nefelibatas" pejorativamente para designar os integrantes da, então, nova estética literária. Estes, por sua vez, acusavam os "velhos” de defensores de valores ultrapassados. Os ataques ficavam mais ao nível pessoal "uma vez que a discussão pouco contém de ideias e teorias de ordem literária" (CAROLLO, 1980, p. 326). Segundo Carvalho, "a importância do simbolismo verificou-se mais no terreno da vida literária do que da literatura, uma vez que criou hábitos, costumes, modas que produziram uma sensivel modificação na paisagem do chamado mundo das letras". (1997, p. 53). O grupo simbolista tornava-se cada vez mais complexo, conforme surgiam novas figuras, não só no Rio, mas também no Norte e no Sul do país, mas entre tudo o que se produzia por toda parte, destacava-se a novidade sugerida pela obra de Cruz e Sousa. O poeta redefiniria os rumos do simbolismo no Brasil e, também, marcaria a vida intelectual de Nestor Vítor.

Nestor Vítor conheceu Cruz e Sousa no Rio de Janeiro, em 1889, antes de ambos mudarem-se definitivamente para a cidade, "no Café Londres, apresentado por Oscar Rosas. Cruz e Sousa estava de passagem no Rio, em suas andanças como ponto da Companhia Ismênia dos Santos" (MURICY, 1969, p. X). De volta a Curitiba, declinou ao convite para assumir o cargo de oficial de gabinete do Governo do Estado e passou a dirigir o Diário do Paraná, órgáo oposicionista. No mesmo ano, em viagem à Desterro, atual Florianópolis, tornou a se encontrar com Cruz e Sousa na redação do jornal Tribuna Popular. Em 1893, já no Rio de Janeiro, estreita laços de amizade com Cruz e Sousa e decide "tomar parte na verdade ativa em nosso movimento literário" (VITOR, 1979, p. 79). "Essa amizade passaria a ser a tônica emocional, com poderosas conotaçóes estéticas e morais, de sua vida e espirito". (MURICY, 1969, XI).Anos mais tarde, Nestor Vítor confessaria que de "quantos amigos intelectuais tenho podido contar, nenhum como Cruz e Sousa, por exemplo, concorreu principalmente para me dar estímulo e inspirar-me paixão na minha fase de combate aqui no Rio" (RIO, 2013,99).Enquanto Nestor Vitor firmava-se como professor e crítico literário, 
Cruz e Sousa sem perspectivas na imprensa e com a ajuda de amigos "obtêm emprego de praticante de arquivista na Estrada de Ferro Central do Brasil, (...) emprego que, embora necessário para a sobrevivência, era-lhe torturante" (JUNKES, 2008, p. 33).

$\mathrm{O}$ ano de 1893 tradicionalmente é considerado o marco fundador do simbolismo no Brasil com o lançamento de Missal e Broquéis. Adolfo Caminha, no mesmo ano, escreveu nas páginas do Gazeta de Notícias: "eu vejo em Cruz e Sousa um poeta originalissimo, de uma rara sensibilidade estética, sabendo compreender a Arte e respeitá-la" (CAMINHA, 1980, p. 186). Recusa-se, todavia, a encaixar o poeta em alguma escola literária, "sua escola é seu temperamento, a sua indole, e este é o maior elogio que se pode fazer" (CAMINHA, 1980, p. 187). No ano seguinte, o crítico Araripe Jr., ressaltava a importância do lançamento dos livros de Cruz e Sousa para a literatura brasileira no texto O movimento literário de 1893:

\begin{abstract}
O fato mais interessante que aconteceu durante o ano passado no acampamento das letras, foi a tentativa de adaptaçáo do decadismo à poesia brasileira. A responsabilidade deste cometimento cabe a Cruz e Sousa, autor do Missal e dos Broquéis. Essa transplantação literária tornou-se tanto mais curiosa quando se trata de um artista de sangue africano, cujo temperamento tépido parecia o menos apropriado para veicular a flacidez e frialdade da nova escola (ARARIPE JR., 1963, p. 135).
\end{abstract}

Para Araripe Jr. "o decadismo ou simbolismo constitui um simples acidente literário, um sintoma de fenômenos de ordem mais elevada" (ARARIPE JR., 1963, p. 138). Tocando na questão racial, muito em voga na época, destaca:

\footnotetext{
No Brasil grande quantidade de mestiços tem aparecido e brilhado, tanto nas letras e nas artes, como na política e na administração; negros, porém, sem mescla, é o primeiro que se torna notório pelo talento. Era o que faltava para complemento de paridade com os irmãos da América do Norte (ARARIPE JR., 1963, p. 147).
}

Mesmo com algumas críticas positivas advindas de intelectuais não pertencentes ao grupo simbolista, a obra de Cruz e Sousa permaneceu à margem dos meios literários oficiais. Excetuando os integrantes do próprio movimento, aos quais Cruz e Sousa era reverenciado como um mestre. João do Rio ironiza essa relação aludindo a Félix Pacheco: "Em tempos que já lá vão, o bizarro poeta foi quase o sacerdote magno de uma igreja que tinha por Deus Cruz e Sousa”. (RIO, 2013, p. 136). O próprio Félix Pacheco, em seu discurso de posse na Academia Brasileira de Letras, em 1913, lembrou que na estreia de Cruz e Sousa em livro, com exceção de Araripe Jr., "todos se conclamaram contra o esteta novo e estranho, apedrejando-o como um vazio e campanudo arrumador de frases". (PACHECO, 1981, p. 93). A dicotomia velhos e novos se fazia presente e direcionava as agressóes e/ou defesas a Cruz e Sousa, "alvo dos ataques mais fortes dos velhos é também o exemplo do rumo tomado pela luta: poucas indagaçóes literárias, ofensas pessoais e zombarias" (CAROLLO, 1980, p. 327). Desde que se mudou para o Rio de Janeiro, Cruz e Sousa teve dificuldades para manter-se financeiramente. "Seu drama tornava-se insuperável: excluido da boa sociedade; excluido das redaçóes jornalisticas e, na mais sentida das exclusóes, não reconhecido em sua arte poética". (JUNKES, 2008, p. 34). O trabalho de arquivista na Estrada de Ferro Central do Brasil, além de não agradar ao poeta, mal dava para prover as necessidades básicas de sua família. Via-se obrigado muitas vezes a recorrer à ajuda de amigos. Como ele mesmo destaca em carta enderença a Alberto Costa, em 8 de maio de 1896: 
Ouso insistir no pedido que lhe fiz por carta, pois acho-me na maior angústia e não tenho outro recurso senão importuná-lo ainda uma vez. Peço-lhe encarecidamente que me sirva, se não em toda ao menos na metade da importância que eu lhe solicitei. As minhas contrariedades e afliçóes avolumam-se cada vez mais. O amigo não pode calcular certamente nem a metade da situação por que estou passando (SOUSA, 2008, p. 649).

O poeta e ensaísta Saturnino de Meireles, um "dos mais dedicados discipulos de Cruz e Sousa. Durante certo tempo, dos Rs250\$000 que ganhava, entregava Rs50\$000 a Cruz e Sousa ${ }^{3 "}$. Além das dificuldades financeiras, Gavita Rosa Gonçalves, com quem se casara em 1893, enfrentava graves problemas psicológicos desde 1896. Tuberculoso, Cruz e Sousa relata a sua condição a Nestor Vítor em carta datada de 27 de dezembro de 1897: "Não sei se estará chegando realmente o meu fim; - mas hoje pela manhã tive uma sincope tão longa que supus ser a morte" (SOUSA, 2008, p. 650). Em janeiro de 1898, obrigado a pedir licença no trabalho, mais uma vez, buscou auxílio ao fiel amigo. "Peço-te para ires ao Escritório da Linha, em S. Diogo, entregar o meu requerimento pedindo licença, por que os dias estão passando e eles já reclamaram esse papel. Qualquer demora me pode prejudicar muito" (SOUSA, 2008, p. 651). Com a piora de sua condição de saúde, Cruz e Sousa partiu, então, para Minas Gerais, convencido pelo próprio Nestor Vítor e amigos próximos, em busca de tratamento para tuberculose. Antes da viagem preocupou-se em deixar com o amigo uma "procuração ou cousa que o valha para poderes todos os meses receber os meus pingues ordenados; como também deixar feito por antecedência o novo requerimento pedindo prorrogação da minha licença" (SOUSA, 2008, p. 653). Três dias antes de morrer em um vagão de trem da EFCB, Cruz e Sousa enviou a sua última carta ao amigo anunciando a sua chegada.

A morte de Cruz e Sousa, em 19 de março de 1898, foi um duro golpe para Nestor Vítor. Em poema homenageando o amigo escreveu: "A Cidade a agitar-se, as Igrejas, os Portos, I - Estes dando p'ra o Mundo, aqueles para Cima / O nada da Cidade, - a miséria e os confortos, - / Ele tudo viveu e refletiu na Rima". Os integrantes do movimento simbolista também expressaram em poemas os seus pêsames. A morte do poeta é "considerada marco da cisão de grupos e da formação de revistas com programas voltadas para a divulgação de sua obra" (CAROLLO, 1980, p. 216). Dentre essas revistas, merece destaque a Rosa-Cruz, idealizada por Saturlino Meireles e dedicada à memória de Cruz e Sousa. A revista publicou quatro números em 1901 e dois em 1904.Ainda conforme Carollo, "pelas revistas e grupos aparecidos no Rio de Janeiro e nas provincias, sobretudo nas últimas, o movimento simbolista continua efervescente, a despeito de certos anacronismos, até a primeira década deste século". (1981, p. 01). Mario Pederneiras, integrante do grupo dos novos, salienta que com a morte de Cruz e Sousa, "o simbolismo enfraqueceu consideravelmente. Os líricos desapareceram do mundo, e se por ai ainda algum existe, dorme comodamente na doce paz de um emprego público, sonhando apenas com o regalo das aposentadorias" (RIO, 2013, 183).

Ainda em 1898, foi publicado o livro Evocaçóes. O próprio Cruz e Sousa começou a organizar a sua publicação, a qual foi levada a cabo por Saturnino de Meireles a quem

Catálogo da Exposição comemorativa do centenário de nascimento de Cruz e Sousa (1861-1961) promovida pela Biblioteca Nacional (p. 17). 
Nestor Vítor confiou os manuscritos que estavam em sua posse, "tendo-se ele offerecido para assumir a responsabilidade material da edição" (VITOR, 1900, p. 183). Podemos perceber aqui, o papel de destaque de Nestor Vítor, dentre os admiradores de Cruz e Sousa, tanto na divulgação quanto na defesa da obra do poeta.

\section{A CONSOLIDAÇÃO DE CRUZ E SOUSA NO CÂNONE LITERÁRIO BRASILEIRO E O LEGADO DE NESTOR VIITOR PARA CRÍTICA LITERÁRIA}

Nestor Vítor, a pedido do próprio poeta, passou a ser o detentor de sua obra não publicada. Além de publicar e divulgar a obra do amigo, militou junto a crítica literária por seu legado. É dele o primeiro estudo mais extenso sobre a obra de Cruz e Sousa. A monografia Cruz e Sousa, escrita em 1896, mas publicada somente após a morte do poeta. A demora na publicaçáo do texto se deu devido ao fato do autor aguardar primeiramente a publicação do livro Evocaçóes que inspirou parte de sua elaboração.

O foco central deste primeiro ensaio, a poesia de Cruz e Sousa, será mantido como uma constante durante toda a produção crítica de Nestor Vítor, haja vista que na Obra Crítica de Nestor Vítor, publicada pela Fundaçáo Casa de Rui Barbosa, dos 187 textos reunidos, em 42 há referências à produção de Cruz e Sousa, em textos que vão desde 1898 até 1930. É o autor mais constantemente citado por Nestor Vítor (SILVEIRA, 2010, p. 37).

Logo no início do texto, Nestor Vitor exalta a sua singularidade, ao afirmar "que até hoje ainda não existiu um artista com qualidades particularmente suas do que Cruz e Sousa" (VITOR, 1969, p. 04). A tônica permanece pelo restante do texto: "Nunca outro escritor conheci de uma estética tão exclusivista, tão direta, um escritor tão inimigo de se fazer solidário com paixóes humanas para com elas efeito, como êste" (VITOR, 1969, p. 10). Sobre a pouca aceitação que até então, a crítica oficial dava a obra, na visão de Nestor Vitor, era devido a genialidade do autor; o gênio, em sua acepçáo, era aquele capaz de ler o futuro, assim proclamava:

Reserve o futuro a êste artista o triângulo no espaço espiritual que melhor lhe aprouver. Restrinja ou dilate sua influência sôbre o Tempo, como mais justo lhe parecer. O que, porém, será impossível negar-lhe é que êle houvesse conquistado legitimamente um domínio, porque estava vazio e pedia um soberano, que fêz dele, portanto, um domínio propriamente seu (VITOR, 1969, p. 14).

Outro ponto defende que a não aceitação da obra do poeta se deu também devido ao preconceito racial:

Cruz e Sousa é um homem prêto, e por tal é a essa qualidade que o mundo lhe há de atribuir muitas das qualidades extraordinárias que são defeitos aos olhos vulgares, e todos os defeitos e deficiências que êle tenha e que tem realmente em sua obra.

Como se os homens de outras raças, por maiores que sejam, não fôssem deficientes e defeituosos também (VITOR, 1969, p. 21).

A questão racial, aliás, é um ponto reincidente quando se fala em Cruz e Sousa. Araripe Jr., ao descrever a sua linguagem poética o chamou de "naufrágo de uma raça" 
(1963, p. 147) e, posteriromente, Sílvio Romero destacouser ele "o caso único de um negro, um negro puro, verdadeiramente superior no desenvolvimento da cultura brasileira" (1981, p. 81).

Nestor Vítor buscou também divulgar a obra do amigo entre os artistas da época. Em 1899, por exemplo, correspondendo-se com Maurice Maeterlinck, lhe enviou a monografia Cruz e Sousa e solicitou licença para traduzir La Sagesse et La Destinée. Maeterlinck não só concedeu a licença como também "propôs-se a apresentar ao mundo de língua francesa o nosso Cisne Negro, caso lhe fosse enviada tradução de suas obras, a qual - João Itiberê da Cunha, antigo colega de Maertelinck, não chegou a efetuar" (MURICY, 1969, XII). Nesse período, apresentou a Sílvio Romero os escritos inéditos de Cruz e Sousa. O fato é narrado, pelo próprio Sílvio Romero: "Devemos à delicadeza do sr. Nestor Victor, grande amigo do poeta e que se encarregou de publicar-lhe as obras póstumas, a ventura de ler os manuscritos do ilustre morto, que nos é hoje plenamente conhecido" (1981, p. 80).

Em 1900, pronunciou "em Belo Horizonte, a convite, conferência sobre Cruz e Sousa" (MURICY, 1969, p. XII). Promoveu com o auxílio de Gustavo Santiago e Oliveira Gomes a publicação de Faróis. Ele mesmo revisou e escolheu o título do livro, já que o poeta "ainda não havia deliberado definitivamente sobre o nome que daria à collecção, em todo caso este que resolvi adoptar foi lembrado por elle, embora n'um tom consultivo, em conversa, horas antes de sua partida" (VITOR, 1900, p. 183).

Ainda sensibilizado pela morte de Cruz e Sousa, desempregado, sentindo-se isolado entre os grupos simbolistas que se aquela morte deixara sem seu fulcro catalizador, resolve partir para a Europa, no que foi auxiliado financeiramente pelo seu irmão Francisco Norberto (MURICY, 1969, p. XIII).

Residindo em Paris, foi correspondente dos jornais $O$ Pais e Correio Paulistano. Obteve modesta colocação no Consulado do Brasil e solicitado pelo amigo Barão do Rio Branco foi professor dos seus filhos. Realizou algumas traduções e revisões para a Editora Garnier. Ao retornar ao Brasil em 1905, trouxe consigo a primeira edição Últimos Sonetos, de Cruz e Sousa, impressa em Paris pelo editor Aillaud. Esse volume foi organizado pelo próprio Nestor Vítor com versos esparsos e inéditos do poeta. Os poemas que compóem este volume lhe foram entregues por Cruz e Sousa "sem título geral, apenas com a declaração do próprio punho do autor de que eram os seus últimos sonetos. Tal declaração foi que sugeriu o titulo adoptado" (VITOR, 1900, p. 183).

A função de Nestor Vítor, assim, supera a de mero responsável pela publicação do poeta, apresentando-se como intérprete das próprias intençôes do autor. Conforme Chartier, se faz necessário distinguir esses dois conjuntos de dispositivos: "os que provêm das estratégias de escrita e das intençóes do autor, e os que resultam de uma decisáo do editor ou de uma exigência de oficina de impressáo" (1991, p. 182). Encontramos aqui um esforço por parte de Nestor Vítor em interferir o menos possível nas intençóes do poeta. Todavia, isso não deixar de influir na forma de distribuição da obra. Principalmente, devido ao

Cruz e Sousa partia para Minas Gerais para tratamento. Da conversa também participou Artur Miranda. 
fato do crítico se recusar a divulgar poesias esparsas, entregues a ele pela viúva do poeta. "Conservo-as como documentos preciosos, mas me parece que deixando de publicá-las como trabalhos de Arte sou fiel às intençöes do autor e correspondo melhor à confiança que elle em mim depositou" (VITOR, 1900, p. 183).

Joáo do Rio relata que ao recebê-lo para uma entrevista em seu retorno para o Brasil, o encontrou transformado. "A violência, aquele ar de pedagogo zangado com que procurava convencer os discipulos, desapareceu" (2013, p. 96). E ainda ironiza: "Três anos antes faria reflexóes a propósito do meu inquérito, reflexóes onde haveria decerto alguns desaforos, alguns axiomas, algumas ironias e muito talento. No momento em que the pedia as suas ideias, entretanto, sorriu". (RIO, 2013, p. 96).

A viagem à Europa estabelece um novo rumo em suas ideias, marcado por "reflexóes ligadas à pátria e sobretudo à missão do Brasil como país dos herdeiros dos latinos" (CAROLLO, 1981, p. 42). Em 1906, assumiu a seção de crítica literária da revista Os Anais, de Domingos Olímpio (autor de Luzia Homem, sob o pseudônimo de Nunes Vidal). Passou a lecionar na Escola Normal e no Colégio Dom Pedro II. Durante a Primeira Guerra Mundial, em 1914, promoveu com Rui Barbosa, José Veríssimo e outros, a Liga Brasileira pelos Aliados.Com a morte de Veríssimo, em 1916, substituiu-o na cadeira de História do Lycée Français (Instituto Franco-Brasileiro). Foi eleito deputado estadual, no Paraná, em 1917. Aceitou, em 1918, uma cadeira na Escola Superior de Comércio (onde chegou a vice-diretor) e teve o seu mandato de deputado renovado em 1919.

Com a publicação das obras póstumas de Cruz e Sousa surgem novas interpretaçôes em relaçáo à sua obra. Vultos do meu caminho (1918), por exemplo, livro de João Pinto da Silva dedicados a nomes importantes da literatura nacional, como Euclides da Cunha e Olavo Bilac, aparece com um capítulo dedicado à Cruz e Sousa. O autor defende que Cruz e Sousa é uma "anomalia" na literatura nacional, um expatriado dentro da própria pátria. "Sob todos os aspectos é um poeta francez, pelo cérebro, escrevendo em nossa língua algumas páginas que só por isso não são universaes" (SILVA, 1927, p. 52). Desse aspecto, segundo o autor, surge a indiferença de muitos contemporâneos em relação ao poeta. Para além da dificuldade de se compreender a escrita de Cruz e Sousa, o autor ressalta o preconceito racial como um dos principais motivos pelo qual permaneceria às margens $\mathrm{da}$ literatura brasileira.

\footnotetext{
Nas rodas officiaes da literatura nacional, Cruz e Souza não passou nunca de um ruidoso autor de coisas bizarras e sem nexo, onde a riqueza iriada, sonora do vocabulário, o abundante verbalismo, serve, unicamente, para dar a illusão dum sentido occulto, a fugidia imagem duma trama philosophica, enffim, que ellas náo têm. Para a maioria, sempre foi um negro pernostico, intolerável como todos os negros dessa especie.
}

Dispensa qualquer comentário essa injustiça, tão revoltante é ella e tão absurda (SILVA, 1927, pp.53-54).

Similar a visão de outros críticos observa que "a sua prosa é inferior a seu verso" (SILVA, $1927,67)$. Por fim, lamenta o isolamento e baixo reconhecimento sofrido pelo poeta e proclama que "de nós todos é que deve partir um movimento unanime de justiça, reivindicando 
para esse extranho e magnifico poeta um alto posto de destaque na longa, intorcível cadeia da evolução artística universal' (SILVA, 1927, p. 72).

Nas primeiras décadas do século XX foram lançadas duas obras fundamentais para a historiografia literária brasileira: História da literatura brasileira (1916) de José Veríssimo e Pequena História da literatura brasileira (1919) de Ronald de Carvalho. No primeiro, não há menções a Cruz e Sousa ou aos integrantes do grupo dos novos.

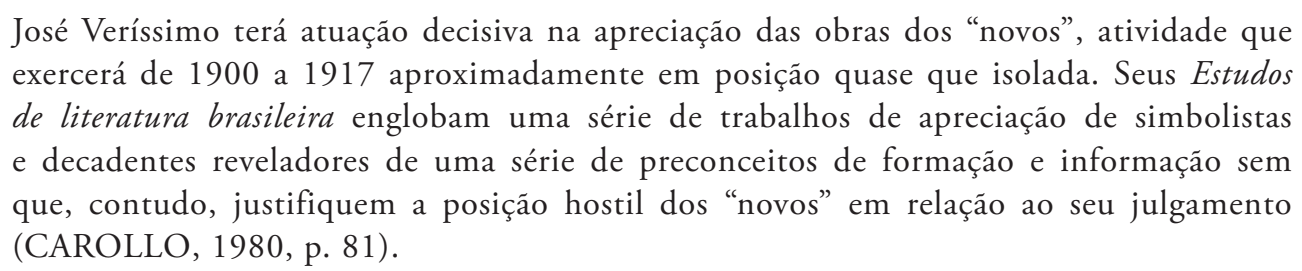

Nestor Vitor destaca que José Veríssimo, por questão pessoais, tinha o pé atrás “com todos os bôhemios ou simplesmente 'malcreados' irregulares" (1924, 187). A História da literatura brasileira de Veríssimo, tornou-se junto com a obra homônima de Sílvio Romero, lançada em 1888, uma das principais referências para se pensar os modelos nos quais foram construídos os cânones da literatura nacional. Já o trabalho de Ronald de Carvalho reserva um tópico específico para Cruz e Sousa e os decadentes. Ao analisar a obra do Poeta Negro, o autor afirma que sua obra "não é, todavia, simplesmente um grande ensaio falhado, como já se tem dito, nem tampouco a maior expressáo da poesia lírica no Brasil, como já se escreveu" (CARVALHO, 1938, p. 348). Destaca que em sua poesia "as obscuridades, os illogismos, a falta de transparência de alguns symbolos são amplamente compensados pela agudeza da sua emoção, pela honestidade da sua queixa immensa de humilhado" (CARVALHO, 1938, p. 350). Discorda de João Pinto da Silva que defendeu que "as palavras $e$ as imagens, imagens intuitivas, de Cruz e Sousa, sob apparente impropriedade, exprimem, em geral, tudo quanto o artista teve em mira quando as escreveu" (SILVA, 1927, p. 54). Para Ronald de Carvalho, poeta possui falhas e vacila no uso de termos que se repetem. Destaca, todavia, que:

Ha em Cruz e Souza, apesar de todas as suas insufficiencias, a força de um precursor. Elle introduzio em nossas letras aquelle horror da forma concreta, de que já o grande Goethe se lastimava no fim do século XVIII. E tal serviço, em verdade, não é pequeno, em um paiz onde a poesia flue mais da ponta dos dedos que do coração (CARVALHO, 1938, 352).

No que concerne à prosa simbolista, o autor em um curto parágrafo a define como “despicienda e de valor duvidoso" (CARVALHO, 1938, p. 360). E ressalta que apesar de nenhum prosador se comparar a Cruz e Sousa, o que se tem de mais significativo no simbolismo se encontra na poesia. Os defeitos presentes na obra do poeta, "não justificam $o$ despreso em que ainda o têm as 'rodas officiaes da literatura nacional" (CARVALHO, 1938, p. 352).

Nestor Vítor não ficou indiferente as obras supracitadas e as suas interpretações. Responde brevemente em carta a João Pinto da Silva "que há mérito incontestável de crítico em quem escreveu páginas como as que o senhor nos dá sobre José Enrique Rodó, Cruz e Sousa, Euclydes da Cunha" (VITOR, 1924, p. 79). Em Ronald de Carvalho aponta certa 
superficialidade em alguns pontos de sua análise, não deixa de elogiar, todavia, a atitude perante o "ambiente que respiravam" ainda alheio ao simbolismo.

\footnotetext{
Fazendo crítica ao poeta negro refere-se o meu amigo apenas por cima aos intuitos heróicos do papel que Cruz e Sousa propôs a representar na vida. Não reconhece explicitamente que, pelo relevo que aquele temperamento selvagem deu a tal atitude que, ela começa a marcar mais nitidamente uma nova ética nas nossas letras (VITOR, 1924, p. 197).
}

Em 1923, Nestor Vítor organizou para a editora Anuário do Brasil, a primeira edição, em dois volumes, das Obras Completas de Cruz e Sousa. "A 19 de março, pronuncia discurso no túmulo de Cruz e Sousa, em romaria realizada por motivo do $25^{\circ}$ aniversário de seu falecimento" (MURICY, 1969, p. XVI). No ano seguinte, a convite de Irineu Marinho, passou a contribuir com $O$ Globo, periódico no qual ocorreu a polêmica com Alberto de Oliveira. Em 1928, foi eleito membro da Academia Paranaense de Letras. No ano seguinte, passou a colaborar em $O$ Estado de Sáo Paulo e recebeu o título de Doutor em Ciências Jurídicas e Comerciais, pela Escola Superior de Comércio do Rio de Janeiro. Deixou a crítica do $O$ Globo em 1931. Continuou a lecionar no Instituto de Educação, na Escola Superior de Comércio e no Liceu Francês. Faleceu no Rio de Janeiro, na tarde de 13 de outubro de 1932, aos 64 anos de idade.

\section{CONSIDERAÇÕES FINAIS}

Nestor Vítor aparece como o primeiro nome a partir em defesa do Poeta Negro e do valor estético de sua obra. Entretanto, "a sua posição como crítico náo pode ser limitada a esta preocupação e a sua atividade de crítica não pode ser comprometida pela aparente parcialidade com que teria defendido o amigo" (CAROLLO, 1980, p. 321). O crítico paranaense, com exceção da polêmica com Alberto de Oliveira, mostrava-se um crítico equilibrado em seu trabalho. A produção intelectual de Nestor Vitor é composta por sete volumes de crítica: Cruz e Sousa (1899), A Hora (1901), Três Romancistas do Norte (1915), Farias Brito (1917), A Critica de Ontem (1919), Cartas à Gente Nova (1924) e Os de Hoje: Figuras do Movimento Modernista Brasileiro(1938); três ensaios: O Elogio da Criança (1915), Folhas que ficam e $O$ Elogio do Amigo (1921); dois volumes de viagem: Paris: Impressóes de um Brasileiro (1912) e A Terra do Futuro: Impressóes do Paraná (1913); os livros de poemas A Cruz e Sousa (1900) e Transfiguraçóes (1902); o de contos Signos (1897); o romance Amigos (1900) e a novela Parasita (1928). Além de artigos em jornais e revistas e cartas enviadas aos seus interlocutores reunidas em Obra Critica de Nestor Vitor organizada pela Fundação Casa Rui Barbosa em três volumes (1969, 1973 e 1979).

Após a sua morte, a maior parte de seu acervo ficou em posse de Andrade Murici, considerado o seu herdeiro intelectual. Junto a Tasso da Silveira, encarregaram-se de exercer em relação à obra de Nestor Vitor papel similar ao que ele fez à Cruz e Sousa. Ambos também continuaram o trabalho de divulgação dos escritos do Poeta Negro. No decorrer do século XX, a obra de Cruz e Sousa passou, gradativamente, a ser fonte de estudos em trabalhos acadêmicos. Um ponto marcante dessa série de estudos foi protagonizado pelo antropólogo francês Roger Bastide, que em seus quatro estudos sobre Cruz e Sousa, 
publicado em 1943 em A Poesia Afro-Brasileira, situou o Poeta Negro na tríade harmoniosa do simbolismo junto à Mallarmé e Stefan George.

Atualmente, Cruz e Sousa tem o seu lugar garantido no cânone literário brasileiro. A obra de Nestor Vítor, por sua vez, salvo o seu uso como documento em trabalhos acadêmicos, encontra-se à margem da história da crítica da literatura brasileira. $\mathrm{O}$ trabalho do crítico, no entanto, como ressalta Clóvis Lopes, é o de "ensinar a ler, ajudar a ler" $(1978,119)$ e de trabalhar em função da literatura, para "revitalização constante do seu acervo" (1978, 120). Se essa afirmação estiver correta, o intelectual paranaense exerceu o seu papel. No final de 2007, os restos mortais de Cruz e Sousa foram transferidos do cemitério Francisco Xavier, no Rio de Janeiro, para Florianópolis, cidade natal do poeta. Também foi editada em dois volumes, custeado pelo governo de Santa Catarina, a sua obra completa. 


\section{REFERÊNCIAS}

ALBUQUERQUE, Medeiros e. Páginas de crítica. Rio de Janeiro: Editores Leite Ribeiro \& Maurillo, 1920.

ARARIPE JÚNIOR, Tristão Alencar. O movimento literário do ano de 1893. In: Obra Crítica de Araripe Júnior. v. 2 (1895-1900). Rio de Janeiro: fundação Casa Rui Barbosa, pp. 101-193, 1963.

BRANDÃO, Gilda Vilela. Notas sobre a recepção do simbolismo na França e no Brasil. Revista Brasileira de Literatura Comparada, v. 12, n.17, pp. 107-132, 2010.

CAMINHA, Adolfo. Novos e Velhos. In: CAROLLO, Cassiana Lacerda. Decadentismo e simbolismo no Brasil: crítica e poética (vol. 1). Rio de Janeiro: Livros técnicos e científicos; Brasília: INL, pp. 181-187, 1980.

CAROLLO, Cassiana Lacerda. Decadentismo e simbolismo no Brasil: crítica e poética (vol. 1). Rio de Janeiro: Livros técnicos e científicos; Brasília: INL, 1980.

Decadentismo e simbolismo no Brasil: crítica e poética (vol. 2). Rio de Janeiro: Livros técnicos e científicos; Brasília: INL, 1981.

CARVALHO, Alessandra Izabel. Nestor Vitor: um intelectual e as ideias de seu tempo (1890-1930). 1997. Dissertação (Mestrado em História) - Setor de Ciências Humanas, Letras e Artes, Universidade Federal do Paraná, Paraná, 1997.

CARVALHO, Ronald de. Pequena História da Literatura Brasileira. Rio de Janeiro: Briguiet e Cia editores, 1937.

CHARTIER, Roger. O mundo como representação. Revista Estudos Avançados, v. 15, n. 11, pp. 173-191, 1991.

GARCEZ, M. H. N. Posfácio: Do simbolismo em Portugal e no Brasil. In: PEYRE, Henri. A literatura simbolista. Trad. Maria Helena Nery Garcez e Maria Clara Rezende Teixeira Constatino. - São Paulo: Cultrix: Ed. da Universidade de Sáo Paulo, pp. 91-106, 1983.

GOMES, A. M. C. Intelectuais cariocas, o modernismo e o nacionalismo: O caso de Festa. Luso-Brazilian Review, v. 41, n. 1, pp. 80-106, 2004.

GOMES, A. M. C.; HANSEN, P. S. Apresentação: Intelectuais, mediação cultural e projetos políticos: uma introdução para a delimitação do objeto de estudo. In: Intelectuais mediadores: práticas sociais e ação política. Rio de Janeiro: Civilização Brasileira, pp. 07-37, 2016.

JUNKES, Lauro. Cruz e Sousa: da paixão à paixão. In: SOUSA, João da Cruz e. Obra completa: poesia. Jaraguá do Sul: Avenida; pp. 27-62, 2008.

LOPES, Clóvis. A situação do escritor e do livro no Brasil. Rio de Janeiro: Editora Cátedra, 1978.

MURICY, Andrade. Introdução. In: Obra crítica de Nestor Vítor. v. 1. Rio de Janeiro: Fundação Casa Rui Barbosa, pp. IX-XVIII, 1969. 
OLIVEIRA, Alberto de. A propósito de Cruz e Sousa: uma comunicaçáo do poeta Alberto de Oliveira. In: VITOR, Nestor. Obra crítica de Nestor Vítor. v. 2. Rio de Janeiro: Fundaçáo Casa Rui Barbosa, pp. 355-356, 1973.

PACHECO, Félix. Discurso de recepção na Academia. In: CAROLLO, Cassiana Lacerda. Decadentismo e simbolismo no Brasil: crítica e poética (vol. 2). Rio de Janeiro: Livros técnicos e científicos; Brasília: INL, pp. 85-94, 1981.

RIO, João do. O momento literário. [S.I.]: Obliqpres, 2013. Disponível em: https:// play.google.com/books/reader?id=oYpcAAAAQBAJ\&printsec=frontcover\&output=reader\&hl=pt BR\&pg=GBS.PP1. Acesso em: 20 de ago. 2017.

ROMERO, Silvio. Aliteratura 1500-1900. In: CAROLLO, Cassiana Lacerda. Decadentismo e simbolismo no Brasil: crítica e poética (vol. 2). Rio de Janeiro: Livros técnicos e científicos; Brasília: INL, pp. 79-82, 1981.

SILVA, João Pinto. Vultos do meu Caminho. Porto Alegre: Edição da Livraria do Globo, 1927.

SILVEIRA, Alan Valezan. Diálogos críticos de Nestor Vitor. 2010. Tese (Doutorado em Letras), Setor de Ciências Humanas, Letras e Artes, Universidade Federal do Paraná, Paraná, 2010.

SOUSA, João da Cruz e. Obra completa: poesia. Jaraguá do Sul: Avenida; 2008.

Obra completa: prosa. Jaraguá do Sul: Avenida; 2008.

VÍTOR, Nestor. Cartas à Gente Nova. Rio de Janeiro: Annuário do Brasil, 1924.

1900.

Nota. In: SOUSA, João da Cruz e. Pharóes. Rio de Janeiro: Laemmert, p.183,

Obra crítica de Nestor Vítor. v. 1. Rio de Janeiro: Fundação Casa Rui Barbosa, 1969.

1973.

Obra crítica de Nestor Vítor. v. 2. Rio de Janeiro: Fundação Casa Rui Barbosa, Obra crítica de Nestor Vítor. v. 3. Rio de Janeiro: Fundaçáo Casa Rui Barbosa, 1979.

Recebido: 31/9/2017

Aceito: 6/10/2017 